\title{
Demographic Changes in the Aged Populations of Four Nordic Countries
}

\author{
TAPANI VALKONEN \\ Professor \\ Department of Sociology \\ University of Helsinki \\ TIMO NIKANDER \\ Senior Statistician \\ Central Statistical Office of Finland
}

Demographic development is one of the most important factors influencing the situation of the aged. The main features of this development, such as the growth of the old age-groups, are well known and take place in most countries (Meyers, 1982; Aging in the World, 1982). There are, however, also differences in the timing and magnitude of these changes. This article analyzes similarities and differences in the demographic development of the aged populations in four northern European or "Nordic») countries, Denmark, Finland, Norway, and Sweden. The countries are economically and socially rather similar, but there has been differences in their demographic development. For example, the transition from high to low levels of fertility and mortality took place later in Finland than in the other three countries (Dyrvik, 1979, 99).

The article is based on official statistics on the actual demographic development in 1960-80 and on population projections for the period 1985-2010. For Finland the projection of The Social Insurance Institution and for the other countries the projections prepared by the national central statistical offices are used (for sources see p. 18).

The analysis of the development of the elderly population is complicated by the fact that the limit of old age can be chosen in many different ways. This paper concentrates on persons 75 years old or older. From a gerontological point of view, as well as from the point of view of health and social policy, this age-limit is more relevant than, for example, the typical retirement age-limit of 65 years. If not mentioned otherwise, the aged population in this paper means persons 75 years old or older.

\section{The sizes and growth rates of the aged populations}

In all of the four countries the size of the aged ( 75 years old or older) population grew rapidly from 1960 to 1985 (Figure 1). In Sweden, Norway, and Denmark the increase was a little less than 100 percent and in Finland 150 percent during this 25 -year period. According to the projections, the increase will continue in all of the countries until the end of this century. After that there will be a decline in Sweden, Norway, and Denmark, but the growth is projected to continue in Finland.

The total populations of the Nordic countries have grown only slowly and, consequently, the share of the aged in the total population has grown rapidly (Table 1). The current percentage of the aged population is somewhat different in the four countries. In 1985 it was highest in Sweden (7.4 percent) and lowest in Finland (5.1 
F i g u r e 1. Population aged 75 years or older in four Nordic countries 1960-1985 (actual) and 1986-2010 (projected).

Per

1000

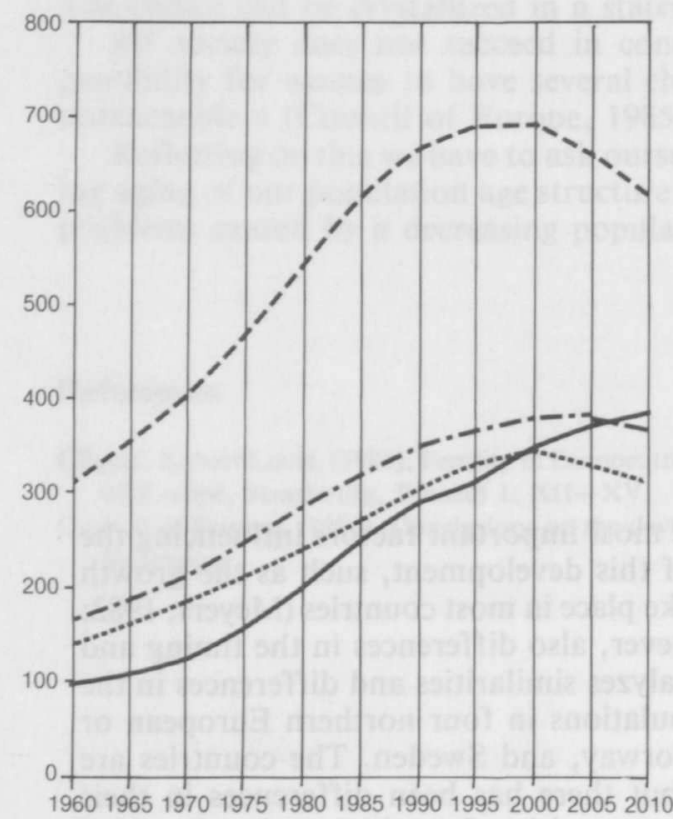

$\mathrm{F}$ i g u r e 3. Average annual growth (percent) of the population aged 60 and over in four Nordic countries 1960-85 (actual) and 1986-2010 (projected).

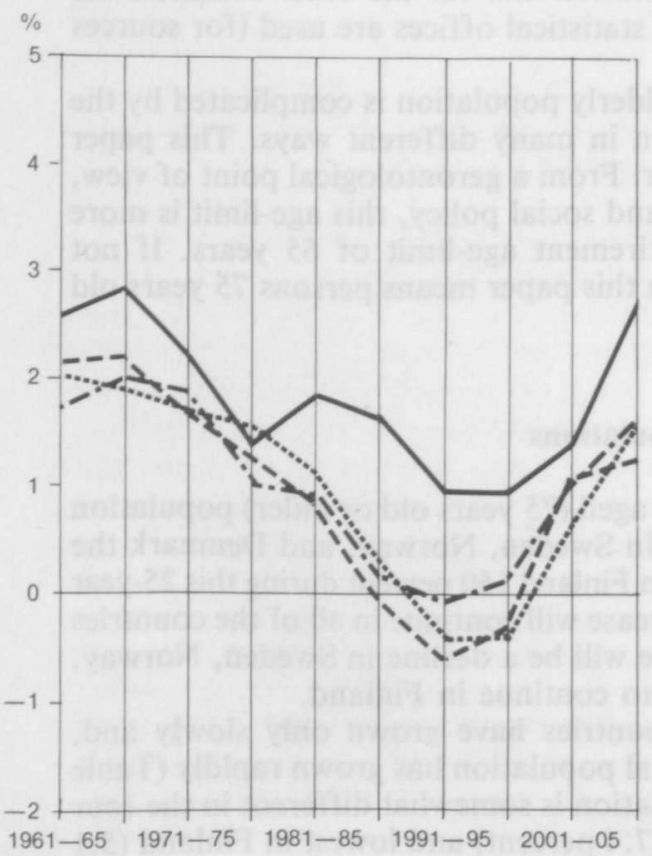

Figure 2. Average annual growth (percent) of the population 75 years and older in four Nordic countries, 1961-85 actual growth, 1986-2010 projections.

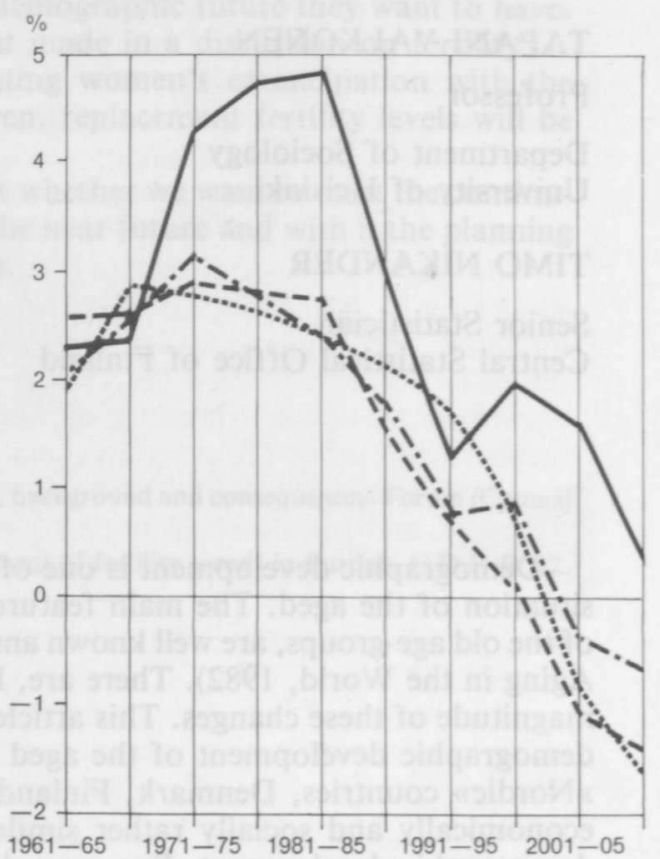

F i g u r e 4. Percentage of women of the population 75 years old or older in four Nordic countries 1960-85 (actual) and 1986-2010 (projected).

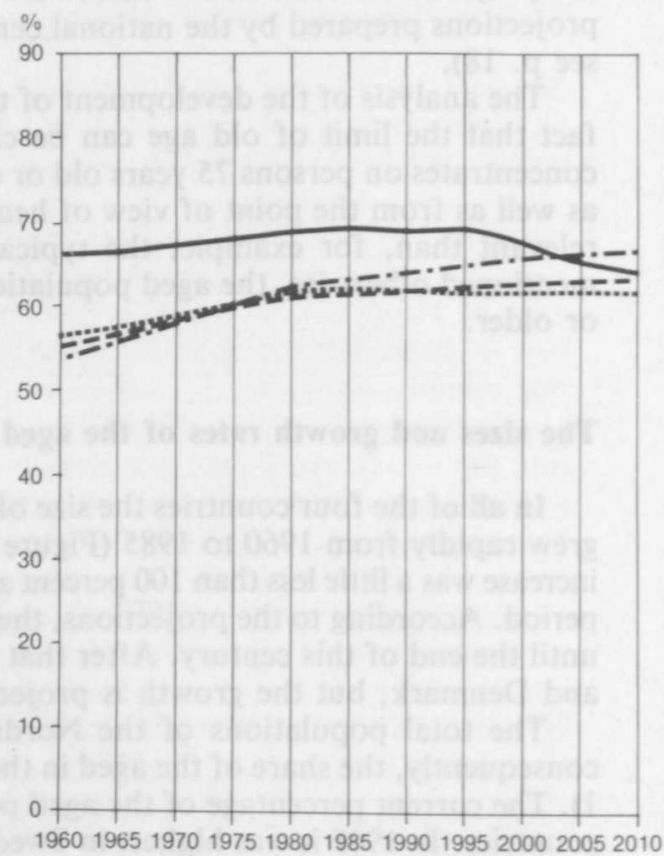


$\mathrm{T}$ a b l e 1. The population aged 75 or older in percent of the total population in four Nordic countries in 1960, 1985, and 2010 (projected).

\begin{tabular}{|lccc} 
Country & $\begin{array}{c}1960 \\
\%\end{array}$ & $\begin{array}{c}1985 \\
\%\end{array}$ & $\begin{array}{c}2010 \\
\%\end{array}$ \\
Denmark & 3.7 & 6.3 & 7.3 \\
Finland & 2.2 & 5.1 & 7.6 \\
Norway & 4.0 & 6.6 & 7.1 \\
Sweden & 4.2 & 7.4 & 7.5
\end{tabular}

percent). It is interesting that by the year 2010 the differences between the countries will almost disappear. In Sweden the percentage will be approximately the same as in 1985 and the other countries will reach the level of Sweden by the year 2010 .

The annual rate of growth of the aged population shows how much growth is needed in the services for old people to keep the quality of the services constant. For example, the current growth rate of the aged population in Finland is about 4 percent per year. An annual increase of 4 percent in personnel, space, and other resources is, therefore, needed only to respond to the demographic change in this age-group. Furthermore, a higher rate of growth in the resources is needed, if the aim is also to improve the quality of services.

Figure 2 shows the average annual growth rates of the aged population for the 5-year periods in 1960-2010. The development is surprisingly similar in Sweden, Norway, and Denmark: the annual growth rate has been approximately 2.5 percent per year until now, but it will decline rapidly and become negative during the first decade of the next century. The period of need for the rapid expansion of services for the aged is, at least temporarily, coming to an end in these countries.

In Finland the situation is different: the growth of the aged population was extremely rapid, almost 5 percent per year, in 1976-85. Although the growth rate is diminishing, the growth itself is expected to continue into the next century.

Figure 3 shows, for comparison, the annual growth rates of the population 60 years old or older. The growth rate of the aged population defined in this way has been smaller than that of the over 75 -year-olds. The number of the 60 -year-olds and older is projected to stabilize or decline in the other countries except Finland in this century. This is due to the small birth cohorts of the 1920s and 1930s. On the other hand, an increase is projected to take place in the beginning of the next century. This is due to the baby boom cohorts born after World War II. These cohorts will also cause an increase in the size of the population 75 years old and older after the year 2020. This new wave of increase of the aged population will, however, not be discussed in this article, which concentrates on the development from 1960 to 2010.

\section{Sex and age composition}

The majority of the aged population are women, and this majority has grown since 1960 (Figure 4). Sweden, Norway, and Denmark have had an almost identical development. The percentage of women has grown from about 55 percent to 62 percent. In Finland the percentage of women is considerably higher than in the other countries. This is due to the exceptionally large difference between the female and male mortality in Finland.

It is generally thought that the feminization of the aged population will continue. The projected development of the percentage of women shows, however, that the current percentage of women will remain almost constant in Sweden and Norway. In Finland, a considerable decrease is projected to take place after 1995; Denmark is the only one of the four countries, in which the growth of the female majority is projected to continue. As a result, the differences between the countries are small in 2010 and the percentage of women varies between 62 and 66 percent in this agegroup. 
A trend common to all the four countries, as well as to other populations in which mortality has declined, is the rapid growth of the "oldest old" age-groups (Figure 5). As a consequence of this trend, the share of the over 85 -year-olds of all over 75 -year-olds, rises from the current $15-20$ percent to $25-29$ percent in 2010 . The timing of this change varies somewhat from country to country. For example, in Finland the percentage of the oldest old has been comparatively low, but is going to increase very rapidly, whereas in Sweden the rise is almost linear. The increase of the share of the oldest old has obvious and well-known consequences for the need of services for the aged.

\section{Components of change in the aged populations}

This section of the article attempts to analyze the causes for the trends and differences described above. It is not obvious, for example, why the growth of the elderly population is much more rapid in Finland than in the other countries or why the growth of the aged population ends in Sweden, Norway, and Denmark at the turn of the century but continues in Finland.

The changes in the size of the aged population depend on changes in two main components:

1. Changes in the number of »new» old persons, which in this article means those who reach the age of 75 . An increase in this »birth rate» of the old population leads to the growth of this population.

2. Changes in the average time people live after reaching the age of 75 . An increase of the life expectancy at the age of 75 leads to an increase of the aged population.

The first of these factors may be further divided into three components:

1. Changes in the size of the birth cohorts born 75 years earlier

2. Changes in the probability of surviving from birth to the age of 75

3. Changes in the net international migration before the age of 75 .

The birth cohorts reaching the age of 75 in the period $1961-2010$ were born in 1886 - 1935. Figure 6 shows the relative changes in the sizes of these birth cohorts in the four countries. A feature common to all of the countries is the decrease in the annual number of births after the early twenties, which was due to the rapidly declining marital fertility in this period. In the earlier development there are differences between the countries. For example, the largest birth cohorts were born in Finland and Sweden 1906-10, in Norway 1896-1905, and in Denmark 1921-25.

The second factor influencing the size of the annual inflow of new old persons is the percentage of persons in each birth cohort, who survive to the age of 75 . The percentages presented in Figure 7 are, however, not actual percentages of surviving persons, but show how large the cohort reaching the age of 75 years is in relation to the original birth cohort. The net result of international migration is thus included in this percentage.

The percentage remaining in the population from birth to the age of 75 years increased steadily in Sweden, Norway, and Denmark in the cohorts born 1886-1910. There was also a clear increase in the probability of this "survival» in Finland, but the level was about 25 years behind the development of the other three countries. The percentage surviving to the age of 75 was thus approximately the same for the Finnish cohort born $1911-01$ as that for the birth cohorts born $1886-90$ in the other three countries.

According to the projections, the percentage of survivors to age 75 will rise further in all other countries except Denmark. The size of the cohort reaching the age of 75 in 2006-10 in Sweden is 65 percent of the size of birth cohort born in 1931-35, but this high percentage is partly due to positive net immigration. In Finland the percentage is projected to be the same as in Denmark, about 50 percent. Denmark is a special case, since the increase of survival is projected to end in the cohort born $1910-15$. 
F i g u r e 5. The percentage of population aged 85 years and older of the total over 75 years old population in four Nordic countries, 1960-85 (actual) and 1986-2010 (projected).

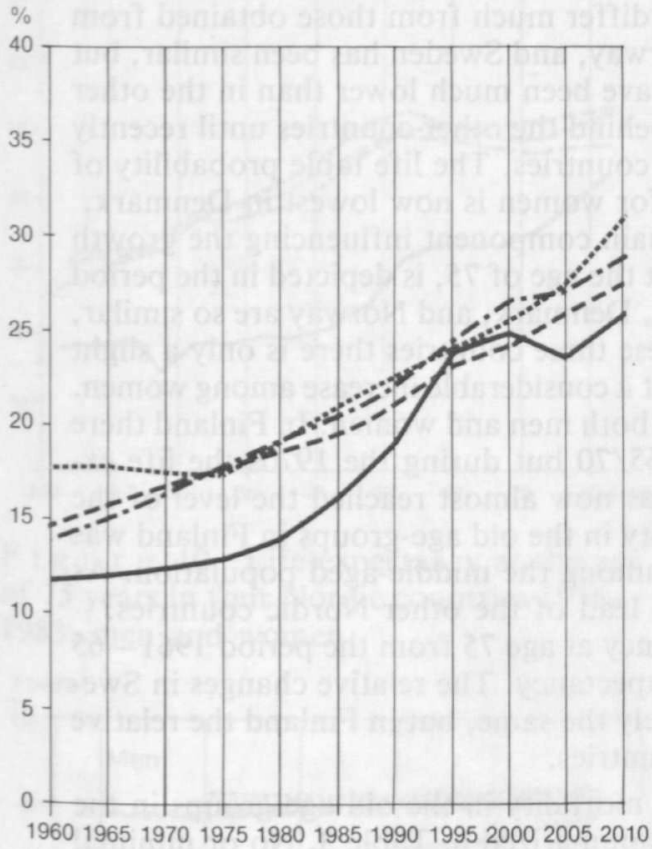

F i g u r e 6. The relative sizes of the birth cohorts born 1886-1935 in the four Nordic countries $(100=$ the size of the birth cohort born 1986-90 in each country).

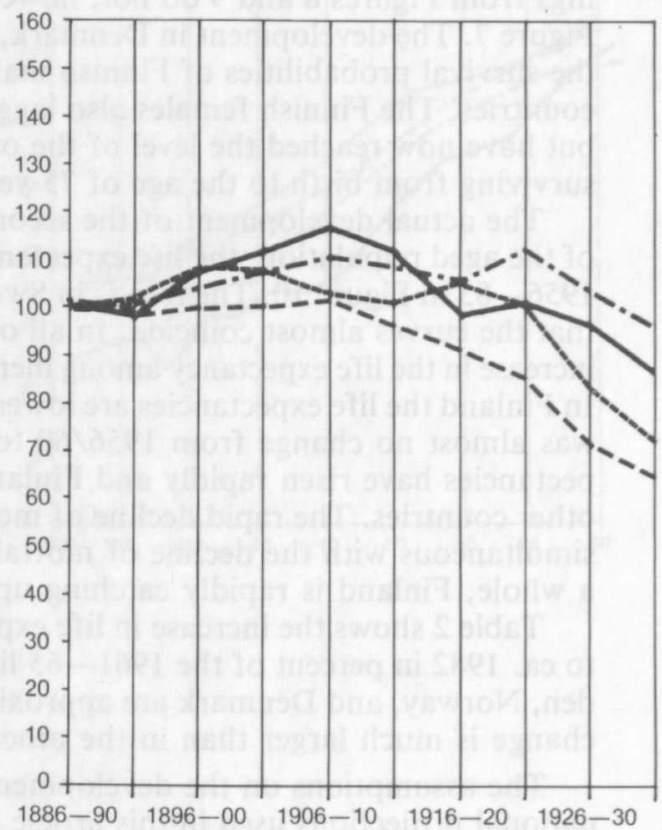

F i g u r e 7. The size of the cohort reaching the age of 75 in percent of the birth cohort born 75 years earlier 1961-85 (actual), 1986-2010 (projected).

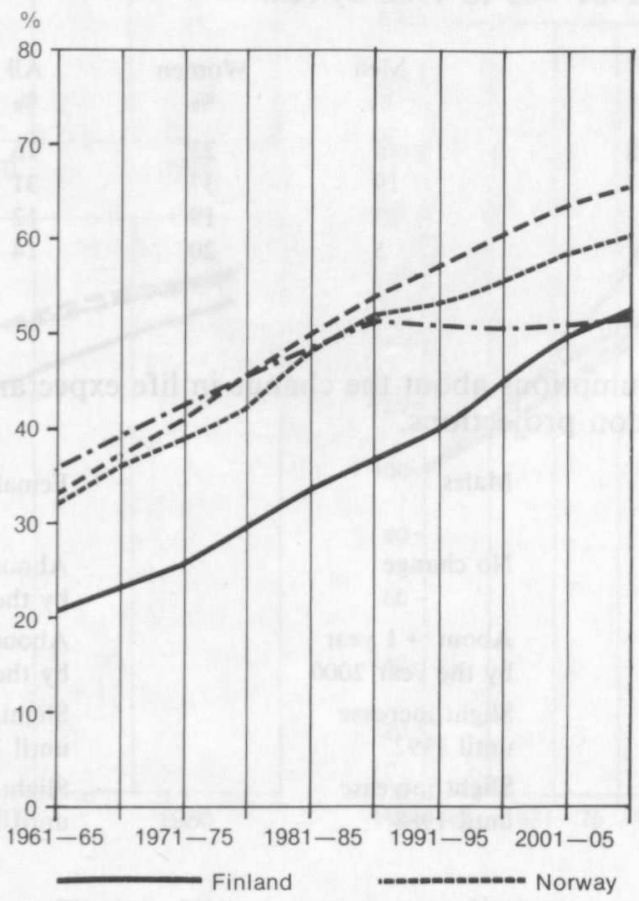


As mentioned before, the data presented in Figure 7 do not show actual percentages of survivors, because they are also influenced by international migration. The results may be checked by using data from the life tables of the four countries. These life tables are not based on cohort data, but on the age-specific death rates for periods. They are thus not directly comparable to the cohort data in Figure 7. The findings from Figures 8 and 9 do not, however, differ much from those obtained from Figure 7. The development in Denmark, Norway, and Sweden has been similar, but the survival probabilities of Finnish males have been much lower than in the other countries. The Finnish females also lagged behind the other countries until recently but have now reached the level of the other countries. The life table probability of surviving from birth to the age of 75 years for women is now lowest in Denmark.

The actual development of the second main component influencing the growth of the aged population, the life expectancy at the age of 75 , is depicted in the period 1956-85 in Figure 10. The trends in Sweden, Denmark, and Norway are so similar, that the curves almost coincide. In all of these three countries there is only a slight increase in the life expectancy among men, but a considerable increase among women. In Finland the life expectancies are lower for both men and women. In Finland there was almost no change from $1956 / 60$ to $1965 / 70$ but during the 1970 s the life expectancies have risen rapidly and Finland has now almost reached the level of the other countries. The rapid decline of mortality in the old age-groups in Finland was simultaneous with the decline of mortality among the middle-aged population. As a whole, Finland is rapidly catching up the lead of the other Nordic countries.

Table 2 shows the increase in life expectancy at age 75 from the period $1961-65$ to ca. 1982 in percent of the 1961-65 life expectancy. The relative changes in Sweden, Norway, and Denmark are approximately the same, but in Finland the relative change is much larger than in the other countries.

The assumptions on the development of mortality in the old age-groups in the national projections used in this article are summarized in Table 3 . No or minimal changes are expected to take place in Norway and Sweden, and among men in

$\mathrm{T}$ a b l e 2 . The relative increase of life expectancy (in percent) at age 75 from the period $1961-65$ to 1982 by sex.

\begin{tabular}{|c|c|c|}
\hline Country & $\underset{\%}{\text { Men }}$ & $\begin{array}{c}\text { Women } \\
\%\end{array}$ \\
\hline Denmark & 6 & 23 \\
\hline Finland & 19 & 37 \\
\hline Norway & 3 & 19 \\
\hline Sweden & 5 & 20 \\
\hline
\end{tabular}

$\mathrm{T}$ a b l e 3. The assumptions about the change in life expectancy at age 75 in the population projections.

$\begin{array}{lll}\begin{array}{l}\text { Country and year of } \\ \text { publications } \\ \text { Denmark (1985) }\end{array} & \text { Males } & \text { Females } \\ \text { Finland (1985) } & \text { No change } & \begin{array}{l}\text { About }+1 \text { year } \\ \text { by the year } 1995\end{array} \\ \text { Norway (1982) } & \begin{array}{l}\text { About }+1 \text { year } \\ \text { by the year } 2000\end{array} & \begin{array}{l}\text { About }+0.9 \text { years } \\ \text { by the year } 2000\end{array} \\ \text { Slight increase } & \begin{array}{l}\text { Slight increase } \\ \text { until } 1992\end{array} & \begin{array}{l}\text { until } 1992 \\ \text { Slight increase } \\ \text { until } 1988\end{array}\end{array}$


$\mathrm{F}$ i g u r e 8. The percentage of survivors from birth to the age of 75 years according to the life tables for the four Nordic countries $1901-c .1983$, men.

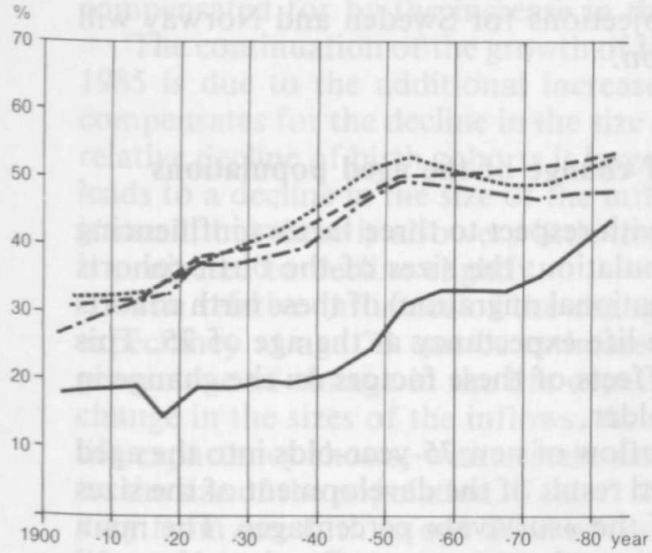

Fig u r e 10. Life expectancy at the age of 75 years in four Nordic countries 19561983, men and women.
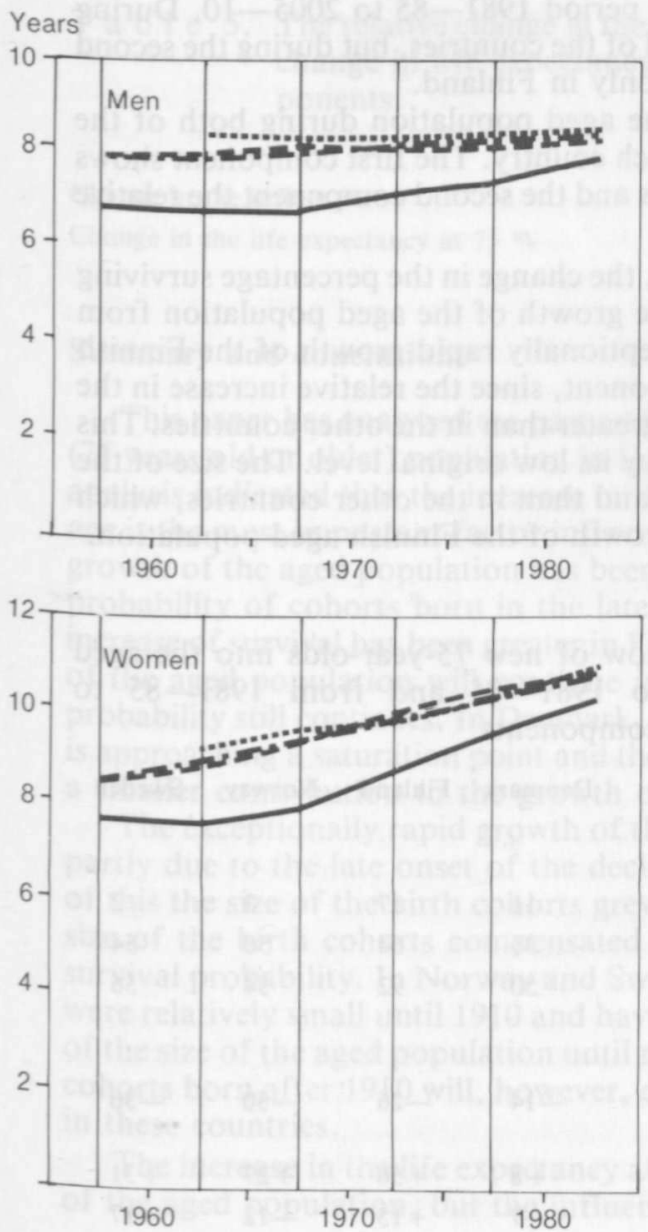

F i g u r e 9. The percentage of survivors from birth to the age of 75 years according to the life tables for the four Nordic countries 1901 - ca. 1983, women.

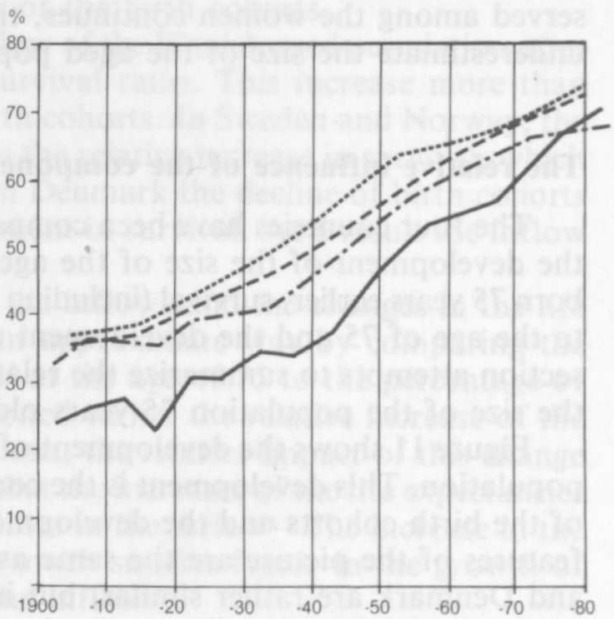

$\mathrm{F}$ i g u r e 11. The inflow of new 75-yearolds into the aged population in four Nordic countries, (relative inflows, 1961-65 = 100 in each country).

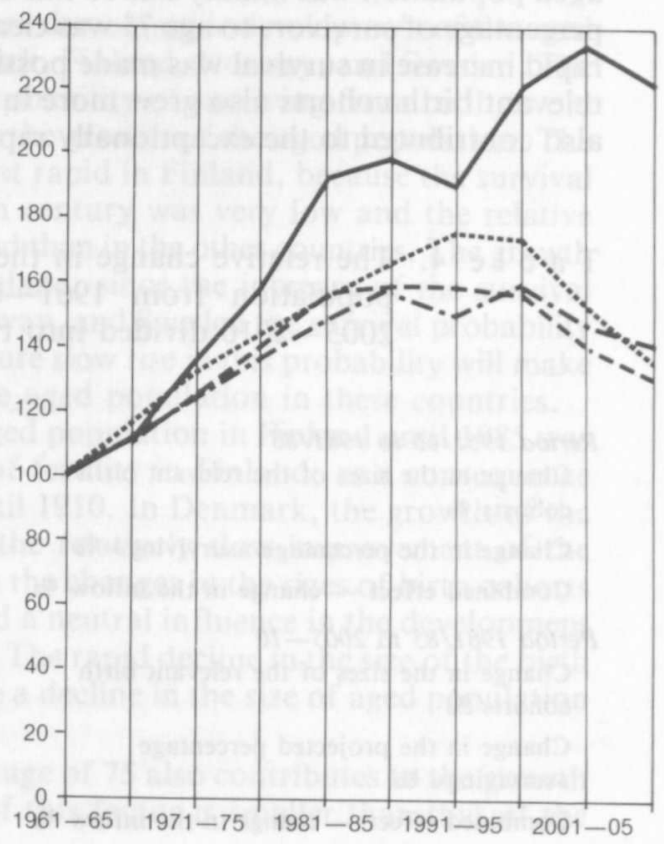


Denmark. In Finland the projection implies an increase of about ten percent for men and women. The increase among Danish women is expected to be of the same magnitude. The central statistical offices thus are cautious about the possibilities of further increases in the life expectancies for the aged population. If the trend observed among the women continues, the projections for Sweden and Norway will underestimate the size of the aged population.

\section{The relative influence of the components of change of the aged populations}

The four countries have been compared with respect to three factors influencing the development of the size of the aged population: the sizes of the birth cohorts born 75 years earlier, survival (including international migration) of these birth cohorts to the age of 75 and the development of the life expectancy at the age of 75 . This section attempts to summarize the relative effects of these factors on the change in the size of the population 75 years old or older.

Figure 11 shows the development of the inflow of new 75 -year-olds into the aged population. This development is the combined result of the development of the sizes of the birth cohorts and the development of the »survival» percentages. The main features of the picture are the same as in most other measures: Sweden, Norway, and Denmark are rather similar, but in Finland the growth of the inflow is much larger. In Table 4 the changes in the size of the inflows are analyzed during two periods: first, the actual development from the period $1961-65$ to $1981-85$ and, second, the projected development from the period 1981-85 to 2005-10. During the first period the aged population grew in all of the countries, but during the second period the growth is projected to continue only in Finland.

The relative change of the inflow into the aged population during both of the periods is divided into two components for each country. The first component shows the relative change in the relevant birth cohorts and the second component the relative change in "survival».

Table 4 shows that the second component, the change in the percentage surviving to age 75 was the major factor explaining the growth of the aged population from 1960 to 1985 in all of the countries. The exceptionally rapid growth of the Finnish aged population was mainly due to this component, since the relative increase in the percentage of survivors to age 75 was clearly greater than in the other countries. This rapid increase in survival was made possible by its low original level. The size of the relevant birth cohorts also grew more in Finland than in the other countries, which also contributed to the exceptionally rapid growth of the Finnish aged population.

$\mathrm{T}$ a b l e 4 . The relative change in the inflow of new 75-year-olds into the aged population from $1961-65$ to $1981-85$ and from $1981-85$ to 2005-2010 divided into two components.

Denmark Finland Norway Sweden

Period 1961/65 to $1981 / 85$

Change in the sizes of the relevant birth

cohorts \%

$\begin{array}{llll}11 & 17 & 3 & 2\end{array}$

Change in the percentage "surviving" $\%$

Combined effect - change in the inflow $\%$

Period $1981 / 85$ to $2005-10$

Change in the sizes of the relevant birth

cohorts \%

Change in the projected percentage

"surviving" $\%$

Combined effect - change in the inflow $\%$
36

50

$\begin{array}{lll}64 & 50 & 54\end{array}$

92
94

$\begin{array}{lllll}-14 & -26 & -30 & -36\end{array}$

$+8+56 \quad+27 \quad+31$

$\begin{array}{llll}-7 & +15 & -12 & -17\end{array}$ 
Sweden and Norway were almost identical with respect to both components. The increase in the size of the inflow was mainly due to a 50 percent increase in survival. In Denmark the 50 percent increase in inflow resulted from a different combination of the two components. The small relative increase in the percentage surviving was compensated for by the increase in the size of the birth cohorts.

The continuation of the growth of the inflow of the Finnish aged population after 1985 is due to the additional increase in survival ratio. This increase more than compensates for the decline in the size of birth cohorts. In Sweden and Norway, the relative decline of birth cohorts is larger than the relative increase in survival, which leads to a decline in the size of the inflow. In Denmark the decline of birth cohorts is small, but there is also very little improvement in survival. As a result the inflow is projected to decline slightly.

The relative influence of the changes in the inflows and the changes in the life expectancy at age 75 can be estimated in an approximate way by comparing the percentage of change in the life expectancies at the age of 75 to the percentage of change in the sizes of the inflows. As mentioned earlier the relative increase of the life expactancy shows, with certain assumptions, the relative impact of this change on the size of the population. Table 5 shows that the increases of the life expectancies vary from one fifth to one third of the increases in the inflows. The increase in the life expectancy of the aged has thus been a much smaller factor in the growth of the aged populations than the increase of the inflows.

$\mathrm{T} \mathrm{a} \mathrm{b} \mathrm{l} \mathrm{e} \mathrm{5.} \mathrm{The} \mathrm{relative} \mathrm{change} \mathrm{in} \mathrm{the} \mathrm{inflow} \mathrm{of} \mathrm{the} \mathrm{aged} \mathrm{population} \mathrm{and} \mathrm{the} \mathrm{relative}$ change in life expectancy at 75 from 1965 to 1985 divided into components.

$\begin{array}{lccccc} & \text { Denmark } & \text { Finland } & \text { Norway } & \text { Sweden } \\ \text { Change in the inflow \% } & 50 & 92 & 54 & 56 \\ \text { Change in the life expectancy at } 75 \% & 16 & 31 & 12 & 14\end{array}$

\section{Summary and conclusions}

This paper has analyzed the past and future demographic development of the aged (75 years old or older) population in Denmark, Finland, Norway, and Sweden. The analysis indicated that the increase in the probability of surviving from birth to old age is the most important factor influencing the growth of the aged population. The growth of the aged population has been most rapid in Finland, because the survival probability of cohorts born in the late 19th century was very low and the relative increase of survival has been greater in Finland than in the other countries. The growth of the aged population will continue in Finland, since the increase of the survival probability still continues. In Denmark, Norway, and Sweden the survival probability is approaching a saturation point and the future slow rise in this probability will make a smaller contribution to the growth of the aged population in these countries.

The exceptionally rapid growth of the aged population in Finland until 1985 was partly due to the late onset of the decline of fertility in Finland; as a consequence of this the size of the birth cohorts grew until 1910. In Denmark, the growth of the size of the birth cohorts compensated for the relatively slow improvement of the survival probability. In Norway and Sweden the changes in the sizes of birth cohorts were relatively small until 1910 and have had a neutral influence in the development of the size of the aged population until now. The rapid decline in the size of the birth cohorts born after 1910 will, however, cause a decline in the size of aged population in these countries.

The increase in the life expectancy at the age of 75 also contributes to the growth of the aged population, but the influence of this factor is smaller than that of the 
decline of mortality in the younger age-groups. The projections made in the Nordic countries are based on rather cautious assumptions about the further decline of mortality in the oldest age groups, although the actual decline in mortality, especially among women, has been substantial in recent times. The projected sizes of the aged populations may, therefore, be too low.

A common feature of all of the four countries is the increase of the percentage of the oldest age-groups. This trend is caused by the decline in mortality in the old age-groups as a consequence of which a larger proportion of persons who have reached the age of 75 also reaches the age of 85 .

The percentage of women of the total aged population has increased until now in all of the four countries. In the future the trends in the sex structure are, however, projected to be different in the four countries, e.g. the percentage of women will decline in Finland but rise in Denmark. These intercountry differences are due to changes in the mortality differentials between men and women.

The analysis showed that Finland differs clearly from the other three countries. The rapid and continuing growth of the aged population in Finland is due to the fact that the demographic transition from high mortality and fertility to low mortality and fertility took place later than in the other countries. In this respect Finland is similar to many "peripheral» countries in eastern and southern Europe. The countries in northwestern Europe, in which the demographic transition took place relatively early will reach a stabilization of the size of their aged populations earlier than the more "peripheral» countries.

\section{References}

Aging in the world: demographic determinants. (1982). World Health Statistics Quarterly (Geneva, Switzerland) $35(3 / 4): 124-132$.

Dyrvik, S. (1979). Comment (The decline of mortality ca. 1740-1850). In Scandinavian Population Studies 5, edited by H. Brunborg and K. Sørensen, pp. 98-103. Oslo, Norway: The Scandinavian Demographic Society.

Meyers, G. (1982). The aging of population. In International Perspectives on Aging: Population and Policy Challenges, edited by R. H. Binstock, W.-S. Chow, and J. H. Schulz, pp. 1-40. New York, N.Y.: United Nations Fund for Population Activities.

Statistical sources

Denmark

Statistisk Tabelvaerk 1963: VI Folk- og boligtaellingen 26. September 1960.

Statistiske meddelelser: Befolkningens bevaegelser 1960-1974.

Statistisk Tabelvaerk: Befolkningen i de enkelte kommuner pr. 1. januar 1975-1982.

Befolkningen i kommunerna 1. januar 1983-1984.

Statistisk Ảrbog 1920, 1960, 1981, 1984.

Befolkning og valg 1985/12 i Statistiske efterretninger Befolkningsprognoser 1985-2010 (2025).

Finland

Official Statistics of Finland VI A: $119-120,122-125,127,129-146,148-150$.

Kansaneläkelaitoksen julkaisuja T9: 27, I Väestöennuste 1985-2050. Helsinki 1986.

Norway

Official Statistics of Norway:

Historiske tabeller over folkemengde, giftermål og dodsfall 1911-1976.

Folkemengden efter alder og ekteskapelig status 31 december 1977-1984.

Historisk statistikk 1978. Oslo 1978.

Framskrivning av folkemengden 1982-2025.

Sweden

Folkmängden och dess förändringar: Befolkningsrörelsen àr 1960.

Folkmängden och dess förändringar: Folkmängdens förändringar 1961-66.

Befolkningsförändringar 1967-1972. Folkmängd 31 dec. 1973-1984.

Sveriges framtida befolkning: Prognos för åren 1983-2025. Stockholm 1983. 